\title{
Novel Approach and Biological Techniques to Improve the Crop Yields under Stress Conditions
} \author{
Nadeem $^{4}$, Muhammad Huzafa ${ }^{1}$ \\ ${ }^{1}$ Department of Botany, University of Agriculture, Faisalabad, Pakistan \\ ${ }^{2}$ Department of Botany, Government Women College University, Faisalabad, Pakistan \\ ${ }^{3}$ Department of Botany, University of Agriculture, Faisalabad, Pakistan \\ ${ }^{4}$ Centre of Agricultural Biochemistry and Biotechnology, University of Agriculture, Faisalabad, Pakistan \\ ${ }^{5}$ Department of Plant Breeding and Genetics, Bahauddin Zakariya University, Multan, Pakistan
}

Syed Asad Raza Shah Naqvi ${ }^{1}$, Maham Saddique ${ }^{2}$, Asma Bibi ${ }^{3}$, Alyan Ashraf ${ }^{4 *}$, Muhammad Mudasser Aslam ${ }^{5}$, Faisal

DOI: $10.36348 / \mathrm{sb} .2021 . \mathrm{v} 07 \mathrm{i} 04.006$

| Received: 09.03.2021 | Accepted: 07.04.2021 | Published: 15.04.2021

*Corresponding author: Alyan Ashraf

\section{Abstract}

Plants have defensive proteins to survive in drought and heat conditions by activation extensive stomata systems. Different factors affected the plant growth such as drought as one of major cause in seed growth inhibition. Biotic as well as abiotic stresses cause changes in morphology and also involve at the molecular alteration or activations of certain genes. Adverse effects of high temperature on cereal crops vary with the timing, duration, and sternness of the heat stresses. Harmful mutations that have drastic effects tend to be fixed in modern breeding pools. Drought also affects the growth of certain growth promoting factors also on turgor. It leads to problems in transport of water to different parts of plants such as xylem and other cells that playing significant role in prompting the plant growth. Different techniques and software's are currently available to under table the nature, type and function performed by each gene in biotic and abiotic stresses. Microarray as one of the best technique used for the gene expression in the plants thus helping the rescuing of disease rate in plants. Different genetic traits have been placed in special groups in order to communicate the stress groups of plants in relation to environment. Different genes are activated under stress conditions that can be potentially recognized and sequenced at the genomics level due to different methods of sequencing used for checking their specific sequence of genes.

Keywords: Plant proteins, biotic and abiotic, genetics, molecular biology.

Copyright $\odot 2021$ The Author(s): This is an open-access article distributed under the terms of the Creative Commons Attribution 4.0 International License (CC BY-NC 4.0) which permits unrestricted use, distribution, and reproduction in any medium for non-commercial use provided the original author and source are credited.

\section{INTRODCUTION}

Biotic as well as abiotic stresses cause changes in morphology and also involve at the molecular alteration or activations of certain genes. While on the other hand, plants have efficient mechanisms to survive under different stresses [1, 2]. It involves the biochemical and molecular mechanism that helps to plant to survive them in different environments such as climate change and other environment changes, drought and slate stresses. These stresses in the extreme positions can cause certain changes in plant structure and some cases even high concentration of salt or extreme temperature leads to in sufficient growth of plant tissues. It also affects the overall growth rate and seed production [3-5].
There are two mechanisms in plants in relation to stresses such as doughnut as well as heat. It mainly involved the roots systems in plants. Plants have defensive proteins to survive in drought and heat conditions by activation extensive stomata systems [6]. The thick layer of cuticle in plant also helps the plants to survive in these conditions. Biotic stresses also leads to overproduction of free radicals that damaged the cuticle layer. While on the other hand, plants have desire antioxidants and enzymes that work against the free radicals and the harsh conditions [7].

Different factors affected the plant growth such as drought as one of major cause in seed growth inhibition. It decrease the stare rate also differentiation processes at the initial stages. High level of drought significantly leads to decreases the growth of plants at 
alarming stage. This implies of the plant that facing drought harsh conditions, pea, alfalfa and rice. It also leads to poor growth of plants also disturbing the mechanism of mitosis that playing important role in cell growth and increase the cell size.

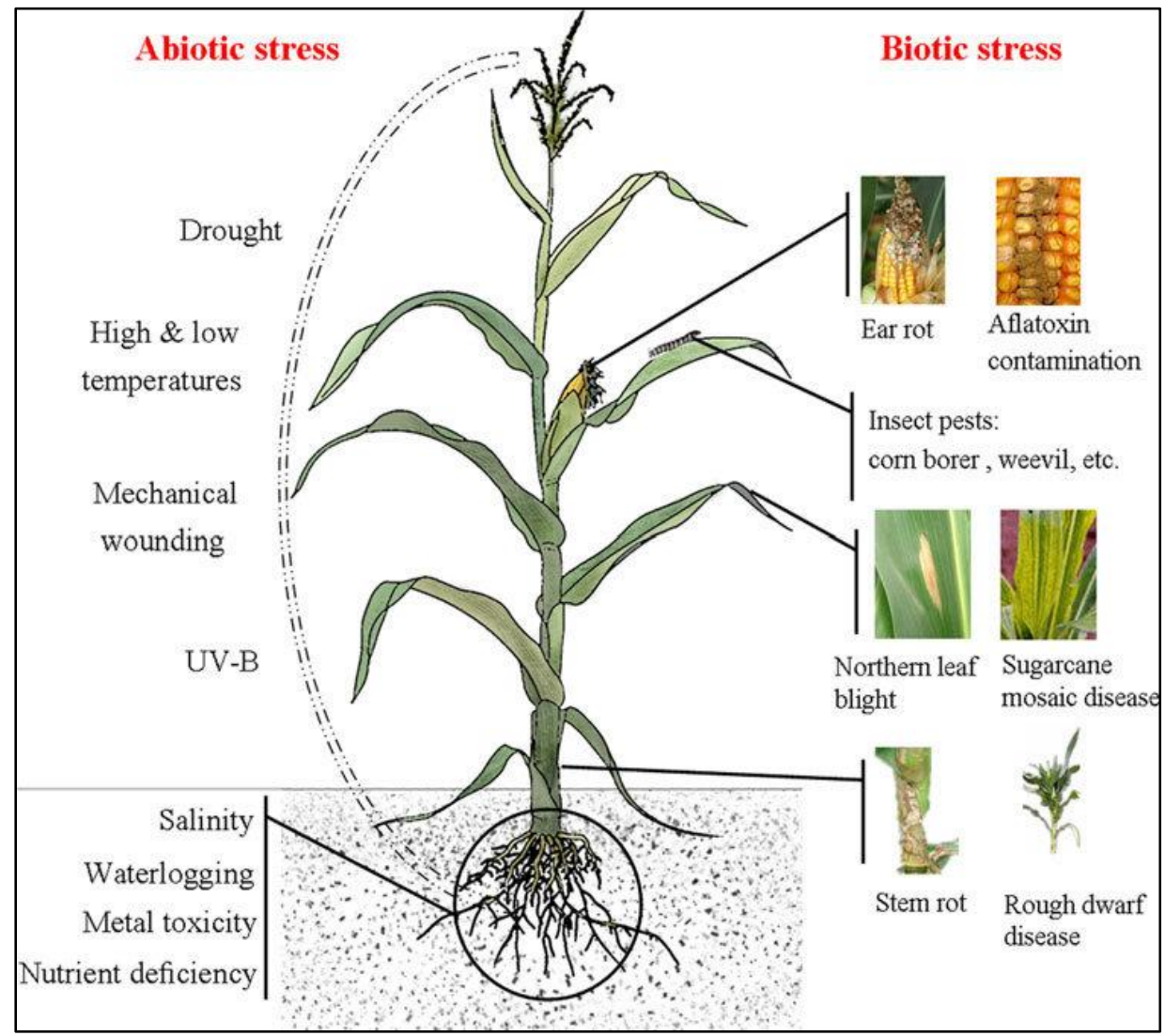

Fig-1: Shows the different conditions of biotic and abiotic stresses

Drought limits the process of cell growth mainly due to the loss of turgor. Water limiting conditions results in impaired cell elongation mainly because of the poor water flow from xylem to the nearby cells [8].

\section{Effect of Heat Stress on Crops}

There are many other factors such as high temperature affect the on the growth of plant by inflicting on the rate of photosynthesis. High temperature also damages the roots of plant cells by altering the cellular and molecular mechanisms. Visible symptoms appear on the roots as well as the damage leaves that ultimately suppress the seedling [9, 10]. Elevated temperatures can reduce the germination potential of the seeds and, thus, results in poor germination and stand establishment. Adverse effects of high temperature on cereal crops vary with the timing, duration, and sternness of the heat stresses. High temperature also influences on the taller plants especially spikes $[11,12]$.

Harmful mutations that have drastic effects tend to be fixed in modern breeding pools. Incremental accumulation of genetic variants with small positive effects on multiple physiological traits during breeding could be easily explained by ongoing selection for performance and yield stability acting on widespread and subtle allelic variation in the functional domains of large regulatory gene families with a known impact on climate adaptation, like PIN and VRN genes. Examples including the yield impacted by the environmental conditions and flow of genes under harsh conditions [13-15]. 


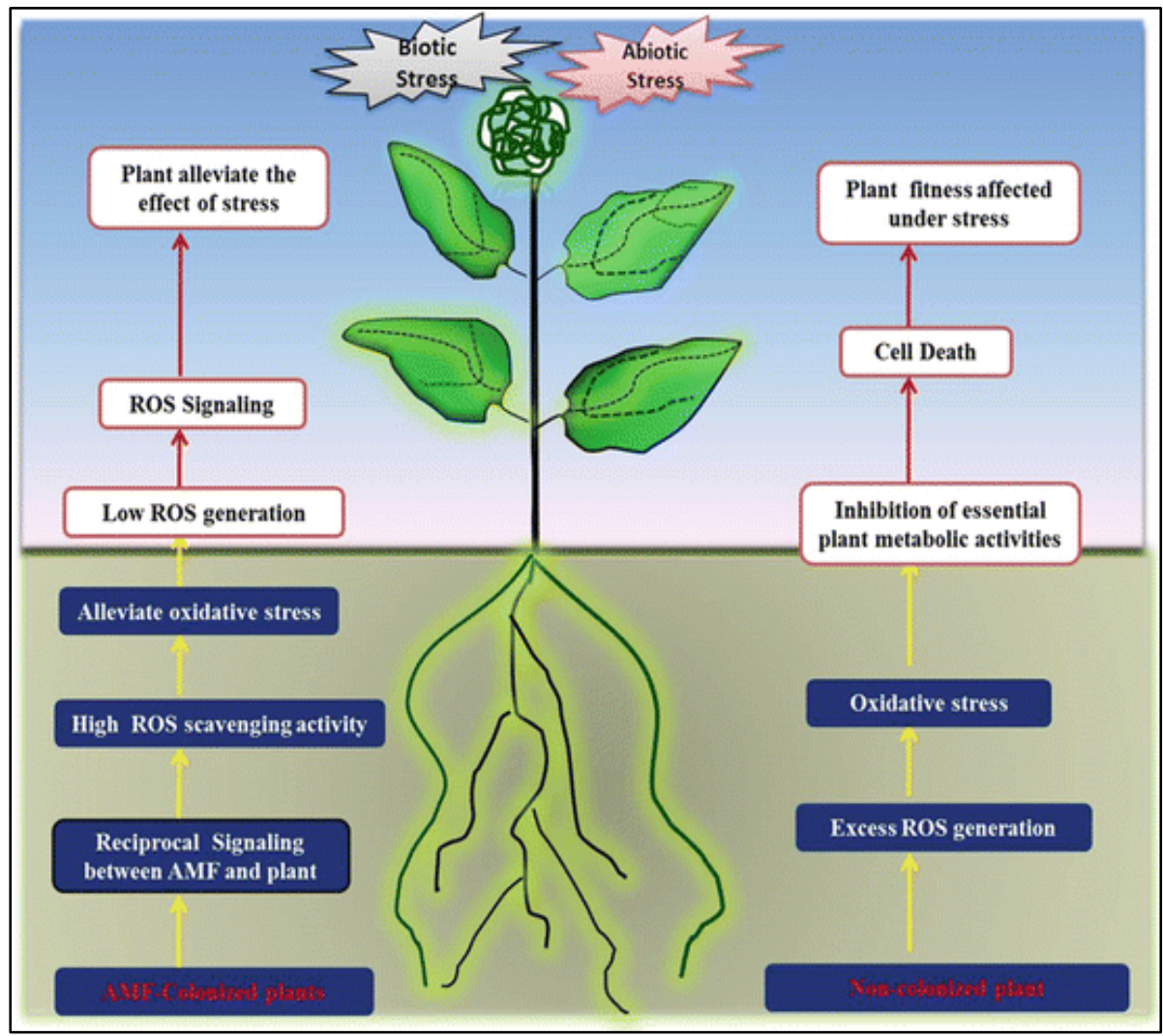

Fig-2: Shows the biochemical changes in plants under different inhibition factors

Different genes of plants can be show resistance against the stress conditions also in harsh environmental conditions. It also leads them to adopt different characters as well as growing more yield and overall economy of world. While breeding activity has directed selection towards increasing the economic yield of cultivated species, natural selection has favored mechanisms of adaptation and survival. More than 80 years of breeding activities have focused on the increase of yield under drought environments for different crop plants. Useful varieties of grains can be achieved through molecular recognition of pathways that can be activated under normal circumstances of activation of prophetess. Scientists have made wheat crops that resist the stress conditions $[16,17]$.

\section{Effects of Drought on Plant Growth}

Drought also affects the growth of certain growth promoting factors also on turgor. It leads to problems in transport of water to different parts of plants such as xylem and other cells that playing significant role in prompting the plant growth. Number of leaves and the size of individual leaf are also reduced under the drought conditions. The expansion of the leaf normally depends upon the turgor pressure and the supply of assimilates. Fresh and dry weights are also severely reduced under the water limiting conditions. It also slows down the plant growth by slowing the processes of photosynthesis thus discusses survival rate of plant in stress conditions. It is needed to adopt drastic changes for parroting the great by rescuing the stresses conditions [18-20].

\section{Functional Genomics}

It is important to understand the nature of genes in different varieties of plant that withstand the stress faced by environmental conditions. The interactions among different genes helpful to understand the nature of molecular mechanism at the gene level. It also helpful to improve the genetic diversity of crops also increase the yield of plants by withstand the environmental stresses. Different techniques and software's are currently available to under table the nature, type and function performed by each gene in biotic and abiotic stresses [20]. 


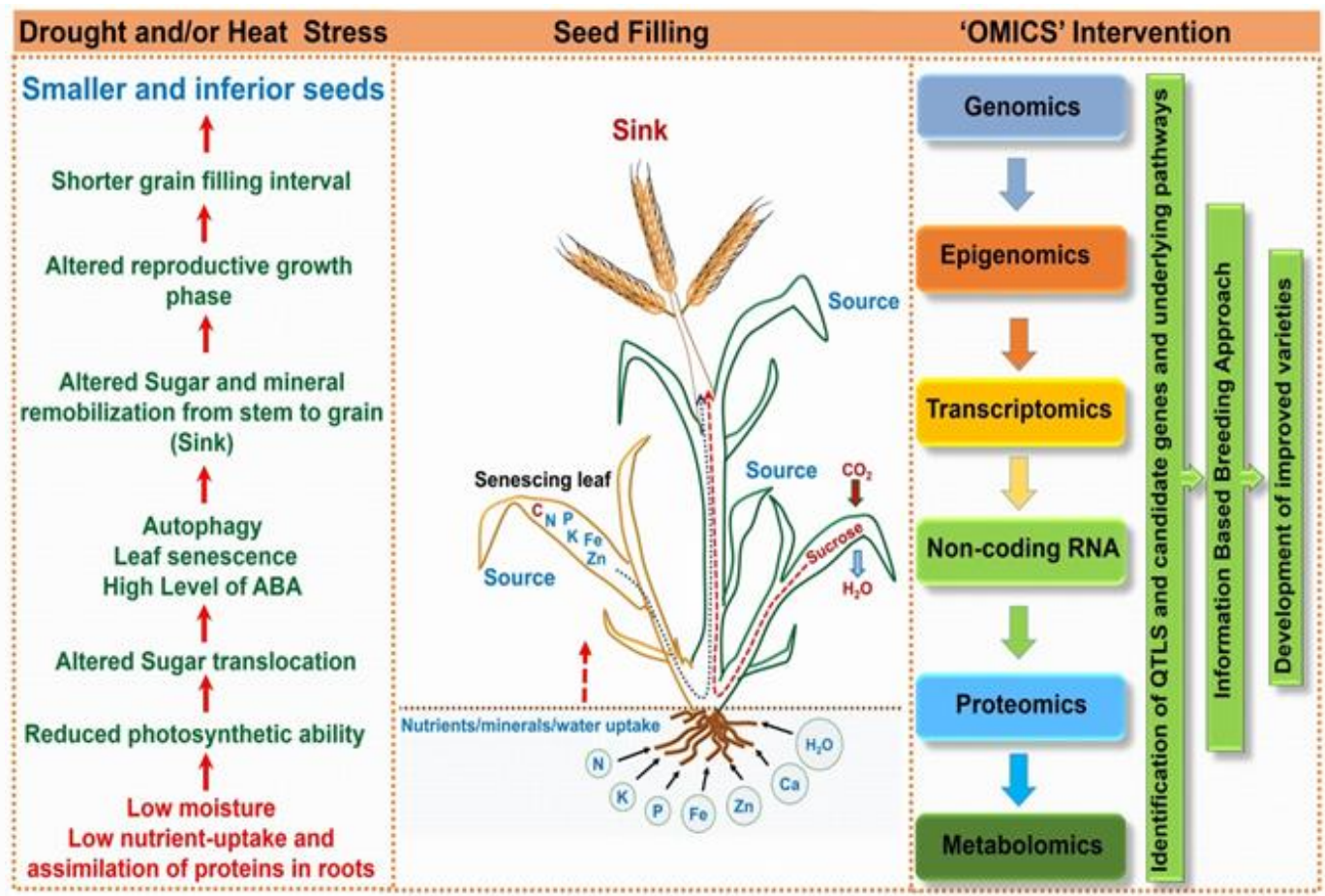

Fig-3: Shows the molecular and cellular pathway and novel approaches to combat stresses

\section{Role of DNA Hybridization in Plants}

Though this technique, variety of genes can be analyzed in the form of single genome. As different plants contains different genes that complicated the system and makes them multiceullalarity of the organisms. It is necessary to categories as well as the shaping them into the signal genome through DNA based hybridization. It has been encouraged by the development of micro-array-based technologies, cDNA micro-arrays and oligo-nucleotide micro-arrays [21, 22]

Other DNA based detection of certain genes at the molecular level to improve the certain adaptation in plants for survival in harsh environment. Microarray as one of the best technique used for the gene expression in the plants thus helping the rescuing of disease rate in plants. Implementation of different new techniques leads to easy laboratory and physical examination of certain characteristics in plants. Both the probe and the target in this approach are hybridization partners. In microarray technology, "probe" is the extension of DNA specific to a particular gene attached to the solid surface, while assembling the microarray itself together with the labeled DNA or RNA strand functional genomics and global gene expression analysis [23, 24].

\section{Role of NGS in Plant Responses}

Different sequences of plants have been compelled through next generation sequencing. Different genetic traits have been placed in special groups in order to communicate the stress groups of plants in relation to environment. Next generation sequencing is used for the organizing the genetic data both industrial and economical point of view for discovery of molecular mechanisms with different genes involved in cascade manner [25, 26].

NGS has tiled a way by making sequencing and re-sequencing of large genomes feasible, a way to exploit plant genomes for breeding improved varieties. In recent times, complete genomic sequences of a number of crops such as maize, rice, sorghum, and soybean along with some model species. Next generation sequencing also provides the sequences of coding as well as noncoding regions also promoter. These are involved in gene regulation to enhance the functionality of different genes involved in different patterns [27-29].

It is unsnuffing knowledge available of abiotic stress that affects the yield and farming processes also agricultural impact. Different genes with high specificity can be inserted into different plants in order to survive in different harsh environmental. Genes and their promoter modifications are important in genetic engineering for resistance against abiotic stresses. For instance, a vast gap exists in the acquaintance about the level of stress tolerance to be developed in crops planned and to be grown on a battered environment, and so, this type of knowledge will definitely be helpful in selecting the measures and techniques for the improvement of stress tolerance [30].

Different molecular and genomic based approached are currently available to the molecular mechanisms of stress that affected that different growth factors for plant development. Large scale of related resources like germplasm lines and inbred lines can be 
Syed Asad Raza Shah Naqvi et al., Sch Bull, Apr, 2021; 7(4): 98-103

developed with extensive knowledge about genetic markers by using the genomic techniques more effectively. Different techniques and industries are used for insertions of genes in the form of gen gun. It is only important that only gene inserted in the right direction in specific plant can survival in different harsh environmental [31, 32].

Different genes are activated under stress conditions that can be potentially recognized and sequenced at the genomics level due to different methods of sequencing used for checking their specific sequence of genes. Each gene has its own promoter site that can be recognized by through sequencers. Therefore, thorough research and breeding efforts are needed to yoke the side effects potentially avoidable by controlling the regulatory genes. So, in order to sort out and understand the data fall irrespective of the availability of large-scale DNA sequencing devices, transcriptomic factors and proteins analyses in a cell, we must also learn to utilize bioinformatics tools that are essential as we have approached the threshold allowing analysis of plants stress response at the entire genomic level $[33,34]$.

\section{CONCLUSION}

However, genomic level sequencing of different plants leads to resistance against the environmental stresses. These effective genomic and molecular identification of genes leads to foundation of novel compounds found in plants that activated and responsible for genes present in stress conditions. It is important to understand the nature of different plants at molecular and cellular level through advanced methods that helpful for control the rate of different diseases.

\section{REFERENCES}

1. Roeber, V. M., Bajaj, I., Rohde, M., Schmülling, T., \& Cortleven, A. (2021). Light acts as a stressor and influences abiotic and biotic stress responses in plants. Plant, Cell \& Environment, 44(3), 645-664.

2. Singh, B., Sran, A. S., \& Sohi, G. S. (2021). Innovative Strategies to Develop Abiotic and Biotic Stress Tolerance in Mustard (Brassicaceae). In Brassica Breeding and Biotechnology. IntechOpen.

3. Sharma, S., Sharma, R., Pujar, M., Yadav, D., Yadav, Y., Rathore, A., \& Gupta, S. K. (2021). Use of wild Pennisetum species for improving biotic and abiotic stress tolerance in pearl millet. Crop Science, 61(1), 289-304.

4. Liu, C., Wu, Y., Liu, Y., Yang, L., Dong, R., Jiang, L., \& Luo, L. (2021). Genome-wide analysis of tandem duplicated genes and their contribution to stress resistance in pigeonpea (Cajanus cajan). Genomics, 113(1), 728-735.

5. Yao, J. W., Ma, Z., Ma, Y. Q., Zhu, Y., Lei, M. Q., Hao, C. Y., ... \& Huang, X. (2021). Role of melatonin in UV- B signaling pathway and UV- B stress resistance in Arabidopsis thaliana. Plant, Cell \& Environment, 44(1), 114-129.

6. Shahid, A., Ali, S., Zahra, T., Raza, M., Shahid, A., Saeed, M. U., \& Javaid, F. Influence of Microbes in Progression of Cancer and DNA Damaging Effects.

7. Iftikhar, A., Shahid, A., Shah, S. S., Ali, S., Raza, M., Ali, E., \& Umbreen, S. Antimicrobial Activities of Selected Medicinal Plant with Potential Role of Chemical Compounds.

8. Qamar, M., Mustafa, G. A., Tariq, S., Rafeeq, H., Rafiq, M., Naqvi, W. Z., \& Kanwal, T. Novel Methods for Detection of Biological Samples, Current Direction and Future Perspectives.

9. Iqbal, Z., Iqbal, M. S., Hashem, A., Abd_Allah, E. F., \& Ansari, M. I. (2021). Plant defense responses to biotic stress and its interplay with fluctuating dark/light conditions. Frontiers in Plant Science, 12 .

10. Naeem, M., Hayat, M., Qamar, S. A., Mehmood, T., Munir, A., Ahmad, G., ... \& Hussain, A. (2019). Risk factors, genetic mutations and prevention of breast cancer. Int. J. Biosci, 14(4), 492-496.

11. Yang, L., Wang, Z., \& Hua, J. (2021). A MetaAnalysis Reveals Opposite Effects of Biotic and Abiotic Stresses on Transcript Levels of Arabidopsis Intracellular Immune Receptor Genes. Frontiers in Plant Science, 12, 241.

12. Shafiq, S., Adeel, M., Raza, H., Iqbal, R., Ahmad, Z., Naeem, M., ... \& Azmi, U. R. (2019). Effects of Foliar Application of Selenium in Maize (Zea Mays L.) under Cadmium Toxicity. In Biological Forum-An International Journal (Vol. 11, No. 2, pp. 27-37).

13. Ahmad, I., Khan, S., Naeem, M., Hayat, M., Azmi, U. R., Ahmed, S., ... \& Irfan, M. (2019). Molecular Identification of Ten Palm Species using DNA Fingerprinting. Int. J. Pure App. Biosci, 7(1), 4651.

14. Usman, G., Muhammad, N., Hamza, R., Usman, I., Ayesha, A., Saqib, U., ... \& Fatima, Q. (2019). A Novel Approach towards Nutraceuticals and Biomedical Applications. Scholars International Journal of Biochemistry, 2(10), 245-252.

15. Singh, J., Singh, P., Vaishnav, A., Ray, S., Rajput, R. S., Singh, S. M., \& Singh, H. B. (2021). Belowground fungal volatiles perception in okra (Abelmoschus esculentus) facilitates plant growth under biotic stress. Microbiological Research, 246, 126721.

16. Satti, S. H., Raja, N. I., Javed, B., Akram, A., Mashwani, Z. U. R., Ahmad, M. S., \& Ikram, M. (2021). Titanium dioxide nanoparticles elicited agro-morphological and physicochemical modifications in wheat plants to control Bipolaris sorokiniana. Plos one, 16(2), e0246880.

17. Naeem, M., Ali, J., Hassan, M. Z., Arshad, B., Rao, M. H. I., Sarmad, M. S. K., ... \&amp; Hassan, M. U. (2019). Novel Approach towards DNA 
Syed Asad Raza Shah Naqvi et al., Sch Bull, Apr, 2021; 7(4): 98-103

Barcoding as a Tool in Molecular Biologyand Biological Activities of Cyclotides with Particular Emphasizes at Molecular Level. In Biological Forum-An International Journal, 11(2), 83-96.

18. Naeem, A., Saddique, S., \& Chand, S. A. (2019). Advancement and Future Directions towards Herbal Treatment for Various Diseases.

19. Khan, M., Khan, A. U., Hasan, M. A., Yadav, K. K., Pinto, M., Malik, N., ... \& Sharma, G. K. (2021). Agro-Nanotechnology as an Emerging Field: A Novel Sustainable Approach for Improving Plant Growth by Reducing Biotic Stress. Applied Sciences, 11(5), 2282.

20. Naeem, M., Ashraf, A., Safdar, H. M. Z., Khan, M. Q., Rehman, S. U., Iqbal, R., \& Ahmad, G. (2020). Biochemical changes in patients with chronic kidney failure in relation to complete blood count and anemia. IJB, 16(1), 267-271

21. Bordoloi, K. S., Krishnatreya, D. B., Baruah, P. M., Borah, A. K., Mondal, T. K., \& Agarwala, N. (2021). Genome-wide identification and expression profiling of chitinase genes in tea (Camellia sinensis (L.) O. Kuntze) under biotic stress conditions. Physiology and Molecular Biology of Plants, 1-17.

22. Hernández, D., Ros, M., Carmona, F., Saez-Tovar, J. A., \& Pascual, J. A. (2021). Composting Spent Mushroom Substrate from Agaricus bisporus and Pleurotus ostreatus Production as a Growing Media Component for Baby Leaf Lettuce Cultivation under Pythium irregulare Biotic Stress. Horticulturae, 7(2), 13.

23. Naeem, M., Hussain, A., Azmi, U. R., Maqsood, S., Imtiaz, U., Ali, H., ... \& Ghani, U. (2019). Comparative Anatomical Studies of Epidermis with Different Stomatal Patterns in Some Selected Plants Using Compound Light Microscopy. International Journal of Scientific and Research Publications, 9(10), 375-380.

24. Liu, H., \& Xue, S. (2021). Interplay between Hydrogen Sulfide and Other Signaling Molecules in the Regulation of Guard Cell Signaling and Abiotic/Biotic Stress Response. Plant Communications, 100179.

25. Ahsan, M., Aslam, M., Akhtar, M. A., Azmi, U. R., Naeem, M., Murtaza, G., ... \& Shafiq, S. (2019). Effect of inoculation of three rhizobial strains on maize hybrids. Journal of Biodiversity and Environmental Sciences, 14(6), 168-177.
26. Hazafa, A., Batool, A., Ahmad, S., Amjad, M., Chaudhry, S. N., Asad, J., ... \& Ghani, U. (2020). Humanin: A mitochondrial-derived peptide in the treatment of apoptosis-related diseases. Life Sciences, 264, 2021, 118679.

27. Rafeeq, H., Ahmad, S., Tareen, M. B. K., Shahzad, K. A., Bashir, A., Jabeen, R., \& Shehzadi, I. Biochemistry of Fat Soluble Vitamins, Sources, Biochemical Functions and Toxicity. Haya: The Saudi Journal of Life Sciences

28. Ghani, U., Naeem, M. Bukhari, S.S.H., Yar, G., Tariq, I., Siddique, S., Nawaz, H.A., Pal, Z.A.A., Nasim, F. and Bukhari, S.A.H. (2019). Prevalence and Risk Factors associated with Hepatitis B and Hepatitis $\mathrm{C}$ and their Correlation with Inflammatory Markers among Southern Region of Punjab. Biological Forum - An International Journal, 11(2): 136-143.

29. Muhammad, N., Umair, R., Azmi, S., Ahmad, Q., Ahmad, M., Tariq, M., Muhammad, A. F. (2019). Reliable vaccine production by using Risk Based Bioengineering Strategies. 6th International Conference on "Sustainable Agriculture in Changing Climate: Strategies and Management, 261.

30. Rafeeq, H., Arshad, M. A., Amjad, S. F., Ullah, M. H., Muhammad, H., Imran, R. K., ... \& Ajmal, H. Effect of Nickel on Different Physiological Parameters of Raphanus Sativus.

31. Zarattini, M., Farjad, M., Launay, A., Cannella, D., Soulié, M. C., Bernacchia, G., \& Fagard, M. (2021). Every cloud has a silver lining: how abiotic stresses affect gene expression in plant-pathogen interactions. Journal of experimental botany, 72(4), 1020-1033.

32. Desaint, H., Aoun, N., Deslandes, L., Vailleau, F., Roux, F., \& Berthomé, R. (2021). Fight hard or die trying: when plants face pathogens under heat stress. New Phytologist, 229(2), 712-734.

33. Sun, C., Liu, L., Wang, L., Li, B., Jin, C., \& Lin, X. (2021). Melatonin: a master regulator of plant development and stress responses. Journal of Integrative Plant Biology, 63(1), 126-145.

34. Harman, G. E., Doni, F., Khadka, R. B., \& Uphoff, N. (2021). Endophytic strains of Trichoderma increase plants' photosynthetic capability. Journal of applied microbiology, 130(2), 529-546. 